\title{
Arbor
}

\section{Don Juan Víctor Abargues de Sostén y la presencia española en el Mar Rojo y Abisinia a finales del siglo XIX}

\section{Montserrat Mañé Rodríguez}

Arbor CLXXX, 711-712 (Marzo-Abril 2005), 825-842 pp.

Durante el siglo XIX, África fue la gran meta de las expediciones europeas, cuyo afán colonialista ganaba a los intereses filantrópicos de épocas pasadas: la curiosidad intelectual dejaba paso a los intereses políticos y económicos. España no fue ajena a este movimiento, si bien los problemas internos y la falta de recursos hicieron que sus exploraciones tuvieran escasos resultados. Abargues de Sostén, gran impulsor teórico de la presencia española en el mar Rojo, fue enviado a Abisinia, la actual Etiopía. Allí realizó una gran labor de observación multidisciplinar, aunque sus informes tuvieran poca repercusión posterior.

\section{Introducción}

La presencia española en los mares de Arabia y el continente africano se retrotrae a la época de los navegantes españoles y portugueses en su ruta hacia las Indias durante los siglos XV y XVI. Pero los españoles pronto abandonarán sus intereses en África, fuera de la costa mediterránea y las islas Canarias, desviando su atención hacia los descubrimientos americanos. A partir de entonces se puede hablar casi sólo de enclaves portugueses, a los que se irán sumando franceses e ingleses principalmente, hasta el gran re- 
parto colonial del siglo XIX en el que alemanes, belgas e italianos cobran un papel preponderante junto a los dos anteriores. Tan sólo sucesivos tratados con Marruecos, especialmente bajo Fernando VI y Carlos III, y el enfrentamiento con Marruecos en 1859-1860, bajo el reinado de Isabel II, traerá de nuevo a la mesa española la cuestión africana, si bien encaminada principalmente a la obtención de territorios costeros y pesqueros frente a las islas Canarias, como reivindicación de "Santa Cruz de Mar Pequeña", un pequeño enclave sobre el que se aseguraban derechos de propiedad desde la época de Fernando el Católico, aunque durante mucho tiempo no se supo muy bien dónde quedaba situado, hasta que finalmente se optó por identificarlo con Ifni como lugar favorable a los intereses españoles ${ }^{1}$. El África Oriental permanece, pues, fuera del marco de los intereses españoles, salvo en lo que al comercio con Arabia y la India se refiere, pero la presencia turca desde el siglo XVI había cortado la comunicación y sólo en el siglo XVIII el tratado de paz y amistad de Carlos III con Turquía (1782) reanudó en cierta manera las relaciones mercantiles. En cualquier caso, los problemas internos españoles -la guerra de la Independencia, la emancipación de las colonias americanas, los pronunciamientos militares, las guerras carlistas- no permitirán hasta época isabelina y sólo intermitentemente plantearse la conveniencia de buscar un enclave en el mar Rojo que habilite una mejor comunicación con las posesiones de ultramar del sureste asiático y Oceanía.

Para entonces, la política exterior española había pasado de mostrar el gran poderío territorial del imperio de los Austria a conformarse con mantener sus fronteras aún muy extensas sin nuevas pérdidas territoriales y el prestigio de varios siglos de dominación ultramarina. Tanto España como Portugal simbolizaban otra época y nuevas potencias estaban decididas a buscar su expansión. Principalmente Francia e Inglaterra, pero también países como Bélgica y Alemania, que empezaban ahora una carrera por lograr nuevos territorios donde colocar sus mercancías y su exceso de población y de donde extraer materias primas que la revolución industrial, en pleno auge, reclamaba ${ }^{2}$.

Estos intereses, puramente mercantiles, van a mudar en interés político especialmente a partir de la construcción del canal de Suez (1869) y la búsqueda de un control mayor de la ruta hacia la India y el extremo Oriente. Hasta entonces África era un continente apenas explorado. Tan sólo sus costas habían atraído el interés de Europa, manteniéndose el interior en un relativo aislamiento suficiente para la creación de distintos reinos africanos que ahora verán amenazada su existencia ante la creciente presencia de exploradores, misioneros, comerciantes, científicos -que, además de auténtico interés propio tendrán apoyo de sus países 
por su papel de justificación para la invasión de que África será objetoy, por supuesto, intrigantes políticos que apoyando a uno u otro reino lograrán su debilitamiento en provecho de las metrópolis europeas.

En esta carrera de obstáculos, España permanecerá al margen hasta mediados del siglo XIX. Su propia situación interna no le permite, en principio, intervenir en nuevas empresas exteriores, pero también una especial idiosincrasia que aún continúa hoy en día hace que los primeros intentos de tipo político y, sobre todo, comercial de buscar un enclave en el mar Rojo, llevados a cabo en su mayoría por particulares de anchas miras, sean rápidamente desestimados por el gobierno, bien por un primer retraimiento económico, olvidando los beneficios que redundarían en el futuro, bien por falta de interés político en todo lo que no afecte a la situación del momento y la opinión pública dentro de España, bien por coincidir, y es lo más triste de todo, con una actitud favorable y, estando en trámites, sucederse un cambio de gobierno que inmediatamente anulaba los proyectos anteriores o un cambio de tipo administrativo y en el trasvase de informes de un departamento a otro se perdían los papeles y todo interés ${ }^{3}$. En esta situación de indecisión se produce la apertura del Canal de Suez y el consecuente desvío de la atención internacional hacia el mar Rojo. Ahora es aún más importante que España logre un enclave en sus costas para facilitar la comunicación con Manila y eso es lo que en parte se propone Don Juan Víctor Abargues de Sostén cuando plantea a la Asociación española para la Exploración del África un viaje de carácter científico por el interior de Abisinia, que proporcione a su vez datos de interés comercial relacionados con el paso por el mar Rojo.

\section{Sociedades y Asociaciones Geográficas: La Sociedad Geográfica de Madrid y la acción española en África}

El siglo XIX fue el de la creación y desarrollo de numerosas Sociedades de Geografía en Europa y América que congregaron a gran número de eruditos y aficionados, así como de políticos y militares en torno a una nueva idea: reunir conocimientos geográficos y, en general, científicos con la sana intención de adquirir un mayor conocimiento universal, así como una mejor comprensión y un acercamiento a aquellas zonas apenas exploradas del planeta que seguían circulando en los relatos como escenario de fantásticas aventuras y leyendas aún más maravillosas. Con esta acción de tipo filantrópico se buscaban hechos, datos, gentes, entrar en contacto con otras regiones del globo y otras culturas. Pero se buscaba también y muy principalmente un conocimiento exacto de la geografía 
desde el punto de vista comercial, político y estratégico-militar. En este sentido, las sociedades geográficas servirían de cobertura ideológica e inocente para planes de otra clase que, cuando no resultaban viables, a menudo dejaban de lado todo interés científico y abandonaban proyectos que de otro modo habrían proporcionado una gran fuente de información y conocimientos a la ciencia del momento ${ }^{4}$.

La primera sociedad de estas características había surgido en 1821 en París, siguiéndola poco después la de Berlín, en 1828, y la de Londres, en 1830, hasta alcanzar, en 1870, una treintena de sociedades en Europa y América, y más de un centenar de sociedades, asociaciones y corporaciones de este tipo en todos los continentes entre 1870 y 1890 . Porque, además de las Sociedades, conforme avanza el siglo, van surgiendo Asociaciones geográficas o coloniales, movidas por intereses comerciales, o Sociedades dedicadas a un tema concreto, como pueda ser la biogeografía o la oceanografía -ya a comienzos del siglo XX-. Y si en un principio se mantendrán gracias a las aportaciones de los socios y las publicaciones, con el tiempo recibirían también del gobierno una cantidad como cualquier otra institución de utilidad pública, con apoyos especiales cuando se trataba de conocer el propio territorio o de proyectos coloniales -México, Brasil, Rusia...-.

En España, los conflictos con Marruecos y la crisis política interna hacen que la creación de una Sociedad geográfica se retrase hasta mediada la segunda mitad del siglo XIX. Restablecida la monarquía y bajo el gobierno estable de Cánovas del Castillo se fundará en 1876 la Sociedad Geográfica de Madrid que, siguiendo el modelo decimonónico, nacerá con una finalidad erudita y científica, aunque su labor fue bastante discreta, esencialmente trabajos teóricos y multitud de propuestas que rara vez contaron con apoyo, salvo en lo que al envío de expediciones de ocupación a Guinea en 1884 y 1886 se refiere ${ }^{5}$. Algo más activa será la Asociación española para la Exploración del África ${ }^{6}$, fundada un año después, en 1877, por algunos de los socios de la Sociedad, como otras similares creadas a partir de una iniciativa de Leopoldo II de Bélgica, y cuyos objetivos desinteresados -abolición de la esclavitud en África, conocer su geografía y sus gentes, su biología y geología, sus recursos y, en especial, darles el toque civilizador del que según sus conciencias carecían-, pronto quedarán supeditados a los intereses políticos y económicos. Aun así, la Asociación logrará lo que no conseguirá la Sociedad, realizar viajes de exploración fuera de los archivos del país ${ }^{7}$.

En este contexto y con miras puestas en el posible resultado comercial se justificarán expediciones de carácter colonial que, sin embargo, no alcanzarán la consecución práctica de sus objetivos. Un primer proyecto se dirigirá a la costa occidental del África, pero un segundo proyecto de gran 
envergadura de la Asociación será sin lugar a dudas el de la exploración de Abisinia, como se conocía entonces a Etiopía, cuyo objetivo último, la consecución de un territorio junto al mar Rojo, punto intermedio de las naves españolas que iban camino de Luzón, las Filipinas y las Marianas, no llegará nunca a realizarse, como veremos. Sin embargo, este segundo proyecto, amén de acercarnos a un personaje de sumo interés para nosotros, proporcionará datos interesantísimos sobre la vida y costumbres de los pueblos de Abisinia, así como de la naturaleza en su sentido más general, incluyendo los productos de aquellas tierras que tanto podían interesar desde el punto de vista comercial a la España de finales del siglo XIX.

Intentos posteriores de realizar nuevas expediciones, esta vez desde el golfo de Guinea hacia el río Congo, quedaron en papel mojado ante la ausencia de recursos y, sobre todo, la apatía general que se observaba en todo el país frente al creciente interés del resto de Europa. Buscando canalizar de algún modo las miradas de la opinión pública hacia lo que podía significar la acción española en África, se realizó un nuevo intento de concienciación a través de un congreso, en esta ocasión de Geografía Colonial y Mercantil, que se celebraría ya en 1883, buscando unos objetivos económicos que movieran más que los puramente estratégicos a la acción del gobierno y del país en general. Y, sí, se logró la creación de una serie de asociaciones coloniales, como la Sociedad Española de Africanistas y Colonistas, que más tarde sería la Sociedad Española de Geografía Comercial, para posteriormente fusionarse con la Sociedad Geográfica de Madrid y formar la Real Sociedad Geográfica, y que llevaron a cabo una serie de viajes de exploración de sumo interés, pero que a la hora de la verdad tuvieron poco resultado práctico, al menos según los objetivos primeramente impuestos, que no desde el punto de vista científico ${ }^{8}$. De hecho, las labores de estas sociedades y asociaciones, mal que bien, lograron abrir camino a nuevas propuestas, encuentros, viajes y resultados hasta bien entrado el siglo XX y, con diferentes motivaciones, continúan hoy en día ${ }^{9}$.

\section{Juan Víctor Abargues de Sostén y la presencia española en el mar Rojo y Abisinia a finales del siglo XIX}

España había sido una gran potencia territorial, pero el siglo XIX mostraba ya un imperio en decadencia cuyas colonias de ultramar se habían en parte independizado de la metrópoli y las que quedaban mostraban signos evidentes de pronta rebeldía.

Un intento de estrechar la relación con esas colonias se reflejará en la búsqueda de un acercamiento físico a través de contactos marítimos más 
frecuentes y seguros. En este sentido, el mar Rojo aparece como un punto estratégico para salvaguardar esos contactos. Al igual que los portugueses habían hecho desde el siglo XVI, los españoles no buscarán colonizar propiamente, sino bases para una red comercial y, si se quiere, política, en cuanto al carácter de puertos seguros y de abastecimiento en el camino a las colonias del sudeste asiático. En este sentido, la propuesta de Juan Víctor Abargues de Sostén al Ministerio de Estado sobre el modo de mejorar las relaciones comerciales con África, haciendo hincapié en la ausencia de comercio y diplomacia españoles en el mar Rojo, no podría haber caído en mejor momento, si bien no fue atendida, como venía sucediendo a lo largo del siglo ${ }^{10}$. Pero tres años después, en 1879, la Asociación española para la Exploración del África le confiará finalmente la misión de organizar una expedición al mar Rojo, Etiopía y África Oriental.

Aquí comienza nuestro periplo, que no la vida de su protagonista. El hecho de que se le encomendara una misión de este calibre no se debía sólo a su propuesta o su interés, venía avalada por una vida pasada en gran parte en el África Central y Ecuatorial.

\subsection{Un apunte biográfico}

De su vida anterior al viaje por Abisinia poco se sabe, aunque algunos datos hay. Por regla general se acepta que nació en Valencia en 1845, aunque hay quien cree que nació en África de padres españoles y quizá un año después ${ }^{11}$. Parece que estudió arquitectura y marchó muy joven al África Central, lo que contradice su nacimiento en ese continente, donde viviría varios años. Pasó más tarde a Egipto y desde allí fue desde donde envió su propuesta, en 1876, al ministro de Estado, en forma de memoria amplia y documentada, la cual no fue tomada en consideración como hemos visto. Considerando la falta de respuesta, optó por venir a España, donde sabemos que es nombrado Académico correspondiente de la Real Academia de Bellas Artes de San Fernando en marzo de $1877^{12}$, y consiguió interesar en sus proyectos a la Asociación Española para la Exploración de África que finalmente, con apoyo económico del marqués de Urquijo y asentimiento de la Sociedad Geográfica de Madrid, patrocinó la empresa.

A partir de aquí comienza el viaje en sí. A finales de 1880 parte Abargues, llegando a Suez a comienzos del año siguiente. Conocemos su viaje por el amplio relato que él mismo nos hace en su conferencia de 1883 ante la Sociedad Geográfica de Madrid y que fue debidamente publicado ${ }^{13}$, así como por una serie de cartas de recomendación que nos dan noticias fragmentarias sobre su itinerario dirigidas por el entonces Cónsul General de 
España en Egipto don Carlos Rancés y Villanueva a los sucesivos ministros de Asuntos Exteriores del Jedive de Egipto ${ }^{14}$. Su exposición ante la Sociedad Geográfica está llena de datos sobre la geografía, las gentes, la cultura, la fauna, la flora, los productos naturales del país - no hay que olvidar los intereses económicos junto a los científicos- y, de carácter más humano, las relaciones que establece como extranjero con los locales -especialmente con el Negus Juan-, al igual que sus aventuras y los obstáculos con los que tropieza -nada nimios, en varias ocasiones corre grave peligro a manos de ciertas tribus o de la naturaleza misma-, todo ello relatado con el tono tranquilo y exquisito de un caballero decimonónico que prácticamente se hubiera paseado por aquellas tierras y presentara su informe final a la espera de unos resultados consecuentes.

Dichos resultados no llegaron y en la segunda sesión del Congreso español de Geografía Colonial y Mercantil ${ }^{15}$ celebrado a finales de 1883 volverá a incidir en la importancia de disponer de enclaves españoles en la costa del mar Rojo, de establecer cónsules y de abrir mercados, dada la riqueza de productos de los países de la zona. Nombrado socio corresponsal de la Sociedad Geográfica de Madrid, considerado como viajero residente en Madrid, y poco después Cónsul honorario de España en Yedda, puerto de La Meca ${ }^{16}$, encargado de proponer al Gobierno español las personas que podrían ser designadas como agentes consulares en los puertos en que lo estimase necesario, no ve sin embargo otras respuestas a sus esfuerzos.

Sus últimos años los pasó en Egipto, pero de esta parte de su vida conocemos tan poco como de la primera. Parece que debió estar relacionado con los nuevos intentos en 1883 del marqués de la Vega de Armijo, ministro de Estado, y en 1885 de don Segismundo Moret, titular de la cartera de Estado, de buscar enclaves españoles en el mar Rojo ${ }^{17}$. Pero además se dedicó a la antropología y la egiptología, temas que le interesaban desde años atrás ${ }^{18}, \mathrm{y}$ a asuntos literarios, puesto que escribió una novela histórica publicada en 1895 en Egipto, lo que nos sugiere que aún vivía allí por esas fechas $^{19}$. En 1916 lo encontramos de nuevo en Madrid, buscando sin éxito una respuesta a sus ideas y proyectos sobre Egipto y Oriente Próximo. Parece que sufre penuria económica y nadie le apoya ni le atiende, no se le ofrece tampoco ninguna tarea hasta que don Rafael de Roda, ConsejeroDelegado de la Compañía Española de Colonización, le socorre y finalmente le proporciona un trabajo en Larache (Marruecos) a finales de 1917 que desempeñó con esmero, pero cuando Rafael de Roda se retira, sus sucesores prescinden de él. En 1919 y 1920, en estado de pura miseria, sigue implorando en vano ayuda de sus conocidos y termina por refugiarse en un asilo, donde acaba sus días ese mismo año de 1920. 


\section{Montserrat Mañé Rodríguez}

832




Don Juan Víctor Abargues de Sostén...

\subsection{Abisinia y el viaje de Abargues de Sostén}

A finales del siglo pasado, Abisinia era uno de los pocos lugares en África que había logrado mantener su independencia ante la creciente influencia europea. Situada entre el mar Rojo, el valle del Nilo, la zona de los Grandes Lagos y el océano Índico, se mantenía además como un reducto cristiano asediado por la fe musulmana.

La leyenda quiere que el origen del reino se debiera a la unión de la reina de Saba y el rey Salomón, origen que se disputa con el Yemen, cuyo fruto, el rey Menelik, habría dado lugar a una dinastía en el siglo X a. C. de la que, en el siglo I a. C., dicen descender los reyes de la ciudad de Axum, y que estaría en posesión de las tablas de la ley robadas del templo de Jerusalén. Será la rama etíope de los judíos, los halashats, semitas llegados del suroeste de Arabia y de donde procede el nombre de Abisinia. El otro nombre, Etiopía, se lo dan los griegos, el país de las «gentes de rostro quemado", como llama Homero a los nubios, algo más al norte, designando simplemente a los africanos que tienen la cara negra ${ }^{20}$.

La cristianización del país tendrá lugar a partir del siglo IV d. C., con el rey Ezana de Axum, manteniéndose a pesar de la progresiva islamización posterior de esta zona de África. La evangelización llegó de manos sirias, atribuyéndose a dos monjes -Frumencio y Edesio-y, ya en el siglo V, a nueve padres, "Los Nueve Santos", que trajeron el monofisismo y la vida ascética, vinculándose así al cristianismo egipcio, en especial alejandrino. Las conquistas persas y más tarde musulmanas aislarán a Etiopía de Bizancio y Alejandría, evolucionando aisladamente en sus creencias y en su gobierno, puesto que se suceden diversas dinastías y reinos, nada claros, hasta que en el siglo XIII encontramos de nuevo una dinastía en Axum que se considera restauradora de la salomónica. A partir de entonces se mantiene una cierta estabilidad y un crecimiento del reino o reinos que figuran bajo el Negus negesti, rey de reyes, hasta el punto de que en Europa se le identifica con el mítico Preste Juan, también situado en Asia Central y Oriental por las leyendas, debido a su condición aislada de lejano reino cristiano, al que suponen dispuesto a ayudar a Europa en su acción contra los creyentes musulmanes.

Serán los portugueses en el siglo XV quienes entren en contacto directo con este supuesto Preste Juan buscando intercambios diplomáticos -Juan II de Portugal enviará a Alfonso de Paiva y Pedro de Covilhão- que serán aceptados sólo cuando la presión turca ahogue a los cristianos etíopes. En concreto y en vinculación con el viaje de Abargues, como veremos después, en 1541 desembarca en auxilio de los etíopes una expedición portuguesa comandada por Esteban de Gama, hijo de Vasco de Gama, que enviará a su hermano Cristóbal al frente de cuatrocientos soldados. Este grupo luchará valientemente y logrará ciertas victorias hasta que su capitán Cristóbal de 
Gama es apresado, torturado y ejecutado en $1542^{21}$. Aun así, los supervivientes portugueses, unos ciento treinta según parece, deciden quedarse al lado del rey etíope al que ayudan a expulsar definitivamente la amenaza islámica, instalándose a su servicio sin regresar jamás a Portugal ${ }^{22}$. A algunos de sus descendientes conocerá Pedro Páez cuando arribe a comienzos del siglo XVII en su labor de evangelización católica. Distintos reyes, reinos y una cierta anarquía se extenderán sin embargo y ello durará en gran parte hasta mediados del siglo XIX. Abargues de Sostén será afortunado, a su llegada, tras una serie de luchas internas, se ha proclamado rey Juan IV, que se encuentra en su momento de mayor apogeo y le recibirá bien ${ }^{23}$.

Abargues de Sostén, que logrará establecer buenas relaciones con este rey, si bien en cierto momento llega a ser sospechoso de ser un espía para Egipto, conseguirá de él permisos para recorrer el país y sus informes en forma de una serie de conferencias serán una gran fuente de información. En su segunda conferencia del 3 de abril de 1883, hará una descripción pormenorizada de la geografía, de su fauna y flora, de la forma de ser y las costumbres de sus gentes y de su historia remontándose a las leyendas. Sirve de colofón a una primera conferencia, tras su vuelta de Etiopía, celebrada el 20 de febrero de 1883 en la que, junto con la relación de su viaje, el itinerario seguido y los percances más o menos destacados, insiste en el alcance comercial y político que puede llegar a tener la presencia española en las costas del mar Rojo e incluso en el interior de Etiopía.

Su periplo propiamente dicho comienza tras su llegada a Suez. En su estilo decimonónico, él restará importancia en la narración de su viaje a las diversas peripecias por las que atraviesa, graves peligros incluso ${ }^{24}$, si bien no deja de mencionarlas y aún de añadir con lujo de detalles las ocasiones que tuvo de ayudar a otros europeos que se encontraban en dificultades $^{25}$. Tras Suez se embarca hacia el puerto de Massaua, de donde, entre otros datos, señala su importancia comercial para las rutas caravaneras y los barcos que navegan por el mar Rojo. Aquí, como en todos los puntos donde lo cree necesario, amén de su exhortación final y su insistencia en años sucesivos, hará constar más o menos directamente las implicaciones beneficiosas para España que tendría un establecimiento diplomático y comercial.

Volviendo al viaje en sí. A partir de Massaua se adentra en el interior, llegando a los dieciocho días a Adua, capital de la provincia de Tigré, y, habiendo de esperar allí el permiso del rey Juan para entrar en Abisinia y recibirle también, aprovechará entre tanto para recorrer las montañas del Semién, que le permiten hacer una serie de observaciones geológicas y topográficas en gran parte novedosas. Recibe entonces el permiso real y avanza hacia Zebul, al sureste, donde en ese momento se encontraba la cor- 
te itinerante del rey, quien le recibe con gran pompa y honores a juzgar por la descripción de Abargues. Esta primera entrevista es descrita con todo lujo de detalles en lo que a la vistosidad y extrañas costumbres se refiere, si bien encontramos también ciertos prejuicios cuando topa con el carácter o lo que él cree tal de los lugareños, a los que en ocasiones ve como a niños pequeños, así como algún comentario que hoy juzgaríamos racista, aunque en aquel entonces probablemente no era más que la expresión de una reserva ante lo diferente y lo extraño respecto a lo ya conocido. Se sucederán bastantes entrevistas más, al parecer en muy buenos términos, y exploraciones de la zona de Zebul antes de que parta de nuevo hacia el sur, atraviese la región de las tribus de los Raya-Gallas y arribe al lago Haic y al lago Ardibbo, cuyas orillas recorrerá ampliamente haciendo minuciosas descripciones de su flora y fauna así como de su situación en los mapas. Se dirige entonces hacia el este, llega al río Hauasch y forma el proyecto de acercarse al lago Aúsa, muy próximo a la costa del mar Rojo, cuando se encuentra cercado por una de las tribus más peligrosas, los Gallas Dauaris, y debe recurrir al artificio y engaño para, cruzando de noche el ancho río lleno de cocodrilos, alejarse mientras el campamento sin desmontar hace creer a los Gallas Dauaris que siguen allí. Esta nada banal aventura, pues pierde dos hombres, además de dos mulas cargadas, le obliga a retroceder en su camino, dirigiéndose de nuevo al lago Ardibbo y después hacia el noroeste hasta alcanzar el lago Tsana y las cataratas del Nilo Azul que viera el padre Páez dos siglos y medio antes. Es en este punto cuando recibe orden del rey Juan para que regrese, pues se le acusa de ser espía de Egipto, el gran enemigo de Abisinia, con lo que se encamina a Adua, donde se encontraba el rey en esos momentos, no sin antes pasar por Gondar. Gondar había sido la antigua capital de Etiopía y conservaba monumentos y edificios portugueses del siglo XV que Abargues estudiará y fotografiará. Al mismo tiempo, recorriendo los alrededores, hallará la tumba de Don Cristóbal de Gama, antes mencionado, que había quedado ignorada en un valle cercano y cuya historia conocía bien. A su llegada a Adua logra explicarse ante el rey, que le cree y además le ofrece numerosas muestras de afecto, entre ellas la de vestirle de guerrero como se hace a los grandes y que Abargues acepta con gran sentimiento de orgullo, describiéndolo con todo detalle. Llegado este momento, Abargues decide regresar, aunque el rey le reitera su apoyo y su permiso para seguir recorriendo el país, pero las fiebres que ha contraído y la ya escasez de recursos le obligan a volver a Massaua, a Suez y finalmente de allí a Europa. Antes de llegar a España pasará no obstante por Roma a presentar sus respetos al Papa León XIII, quien previamente le había agradecido por carta su labor a favor de los misioneros lazaristas franceses. 


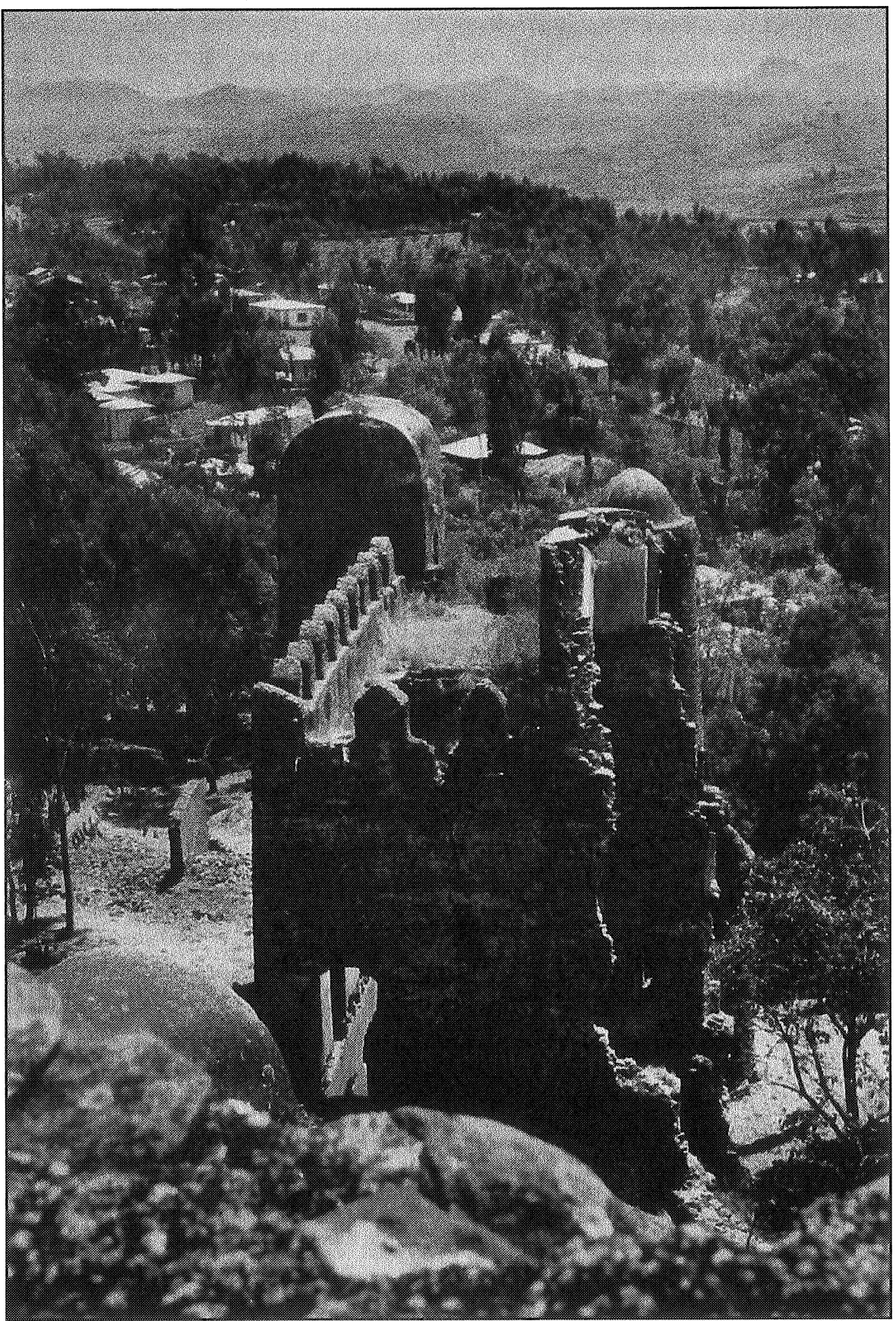

Figura 2. Gondar. Restos del castillo construido en el siglo XVII bajo influencia portuguesa (P. Gourou, 1970, L’Áfrique París, p. 215, il. 174) 


\subsection{Resultados prácticos del viaje}

El viaje había durado algo más de diecisiete meses. Presentará entonces sus informes en forma de conferencias que publicará el Boletín de la Sociedad Geográfica, pero encontrará, como hemos dicho y reiterado varias veces, una total apatía ante sus estudios y proyectos. Su insistencia en años venideros, con ocasión de momentos políticos más favorables, de creación de congresos que tratarán el tema y aprovechando el interés y apoyo de otros personajes con más influencias que él, no logró pese a todo una respuesta por parte del Estado ni tampoco a nivel particular de grandes empresas comerciales. Diversos autores ${ }^{26}$ se hacen eco del error de visión por parte de las autoridades. El propio Joaquín Costa, gran adalid de la acción frente al papeleo y los grandes discursos y que, sin embargo, se vio sepultado por ellos, comentará irónicamente respecto a los resultados del viaje de Abargues:

«Desgraciadamente faltó a los hombres científicos que habían de señalar objetivo de la expedición, el mismo sentido práctico que hasta entonces había faltado a los políticos; y en vez de inspirarse en la conducta previsora de Francia y de Italia, cuyas misiones científicas han encubierto casi siempre propósitos territoriales, sobre la costa, se contentaron, ipechos nobles y desinteresados!, con que el Sr. Abargues de Sostén acopiare datos estimables para la ciencia, sobre el interior de la Abisinia. Desgraciadamente impónese a las veces la realidad, en la acción presente se impuso. Cuando en 1883 regresó de su excursión por la Etiopía el Sr. Abargues, con sus carteras atestadas de fotografías, de plantas y de mariposas, encareció la facilidad con que el Gobierno español podría adquirir un extenso territorio con puertas excelentes en la bahía de Tadysa y situar cónsules (y) abrirse al mercado de Arabia, de la Etiopía y de las provincias orientales de Egipto» ${ }^{27}$.

Es decir, a pesar del carácter científico de la expedición, Abargues no había perdido ocasión de estudiar el terreno comercialmente, lo había presentado en bandeja a las autoridades y, sin embargo, no se había hecho caso ni aprecio de ello.

\section{A modo de colofón}

Se ha insistido mucho en el aspecto colonizador y mercantil de la expedición del Sr. Abargues. No es que sus estudios geográficos, naturalistas y antropológicos no tuvieran importancia, al contrario, fueron apreciados y publicados, incluyendo los mapas costeados por Don Alfonso XII. Pero el contexto en que nos encontramos es el de un movimiento general por parte de Europa 
y América en el que el interés político y económico destaca sobre los estudios puramente científicos que caracterizaron, por ejemplo, las expediciones enviadas previamente por Carlos III en el siglo XVIII. La política colonial del siglo XIX, no necesariamente territorial, aunque a menudo se viera acompañada por este aspecto, primaba los intereses comerciales y, en general, de expansión, no el altruismo, por llamarlo de alguna manera, de los estudios científicos y las expediciones misioneras anteriores. España, por problemas políticos o, más bien, económicos y, sobre todo, una cierta dejadez que no nos ha abandonado, emprendió una serie de proyectos de sumo interés en todos los aspectos, pero que quedaron luego truncados, muchas veces antes de llevarse a cabo, otras a media labor, y otras más, como casi todo lo relacionado con la presencia en el mar Rojo, cuando ya se había dado el primer paso, siempre el más difícil. España quedó prácticamente relegada al papel de observadora atenta, que de vez en cuando intervenía y era escuchada cuando no interfería realmente en los proyectos de los demás países, pero a la que se le cerraba el paso en cuanto intentaba alguna acción propia ${ }^{28}$.

Es cierto que España tardó aún mucho tiempo en alcanzar el grado de desarrollo industrial y social del resto de Europa. Además de los problemas políticos internos, apenas existía una burguesía capaz de apoyar empresas de este calibre y la que había no se arriesgaba hasta ese punto. Los trabajos expedicionarios se realizaron con gran esfuerzo y mucho entusiasmo por parte de sus protagonistas, y los avances expansionistas, en la costa occidental de África, ni siquiera fueron reconocidos por el gobierno hasta que fueron un hecho consumado, algo que ya tenían en la mano. Sólo entonces mostraron interés algunas compañías comerciales al hallar productos que podían comercializar con gran provecho, pero el trabajo primero lo habían realizado miembros de sociedades colonialistas con ideas aparentemente utópicas que, dejados a su suerte, terminaron por volver a sus sociedades geográficas y sus estudios teóricos.

Abargues de Sostén no abandonó nunca su entusiasmo por estos proyectos, siguió insistiendo en cada ocasión, pero no sirvió de nada, al menos en lo que a él le concernió, y sus minuciosas descripciones de la naturaleza y las gentes del país que atravesó resultaron información importante, pero a la que no se le dio un seguimiento, un aprovechamiento intelectual de cierta envergadura. Si al menos se hubieran apoyado los estudios de tipo científico, buscando una continuidad, no se habrían logrado más territorios o zonas de influencia, pero los campos de conocimiento abiertos por Abargues y otros exploradores habrían tenido una prolongación realmente interesante desde el punto de vista científico y humanístico, valores que, después de Carlos III, parecen haber ido cada vez más a la baja. 


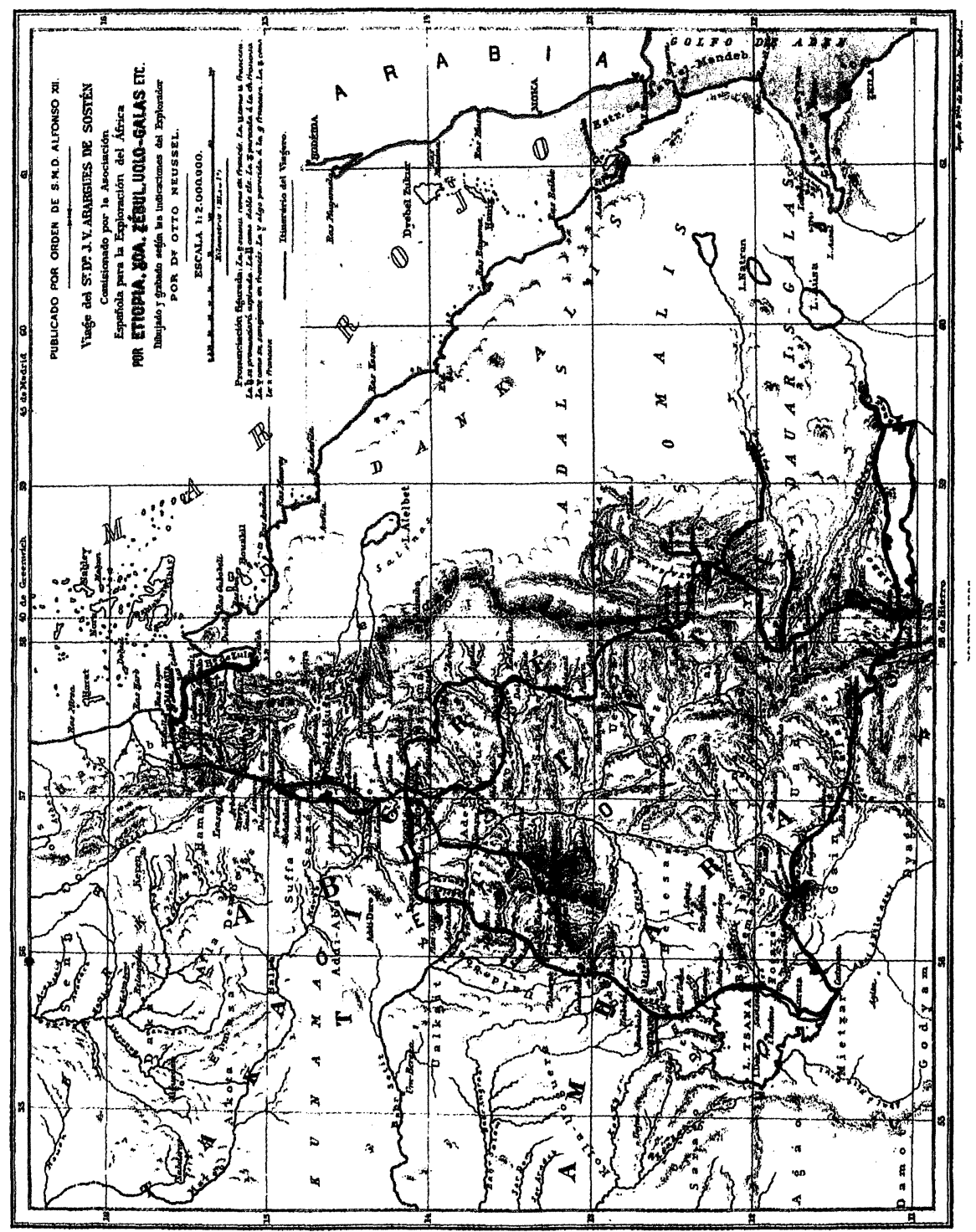

竞 


\section{Montserrat Mañé Rodríguez}

\section{Notas}

1 Rodríguez Esteban, 1998b: 4-5.

Pedraz Marcos, 2000: 27-44.

2 Pedraz Marcos, 2000: 259-266.

3 Vilar Ramírez, 1969: 169-172.

4 Rodríguez Esteban, 1996: 17-25.

Pedraz Marcos, 2000: 65-70.

5 Rodríguez Esteban, 1996: 12-16. «Esta falta de apoyo a la Sociedad Geográfica de Madrid se pone claramente de manifiesto en el estudio de sus cuentas, donde el déficit progresivamente acumulado desde poco después de sus inicios, y que no pudo equilibrarse hasta tres años después del desastre del 98, la obligaron, entre otras cosas y como ejemplo significativo, a reducir el número de los mapas incluidos en su Boletín, habiendo sido en este sentido uno de los mejores boletines geográficos de Europa según afirmaciones de sus contemporáneos, y hasta hubo de ser rebajada la misma calidad del papel empleado en su publicación, (...). Esta penuria económica fue igualmente la causa de que muchas de sus iniciativas apenas llegasen a tomar forma. Sucedió así con la preparación de un tratado de Geografía para las escuelas al no poder ser editado tras su elaboración, con los distintos proyectos para renovar el diccionario geográfico de Madoz y con tantos otros que sólo pudieron ser formulados» (Pág. 16).

6 Rodríguez Esteban, 1996: 74-81.

7 Rodríguez Esteban, 1996: 16, 40-46, 189-284. En este sentido, la labor de la Sociedad Geográfica de Madrid sí será importante, recuperando parte del trabajo que realizaban ya desde el siglo XVIII una serie de corporaciones geográficas, precursoras de las Sociedades, centradas en la geografía histórica. La Sociedad publicará noticias y obras inéditas de la acción colonial de España en América entre los siglos XVI y XVIII, que de otro modo habría quedado olvidada y cubierta por la presencia inglesa posterior y que fomentó un acercamiento con la América de habla hispana en forma de Congresos y de estudios en Geografía histórica, no sólo en América, sino en la España antigua.

8 Rodríguez Esteban, 1996: 81-140.

Rodríguez Esteban, 1998a: 25.

9 www.sge.org

10 Vilar Ramírez, 1969: 174.

11 García Figueras, 1947: 95.

12 García Sepúlveda y Navarrete Martínez, 2005: 20. El académico correspondiente podía asistir a las juntas generales y públicas, con voz, pero sin voto. Debía residir fuera de Madrid y era elegido por la Academia si se consideraba que sus trabajos artísticos eran meritorios o como recompensa por servicios prestados en el descubrimiento o conservación de obras de arte o de documentos interesantes para su historia. A su vez, el académico correspondía con sus ideas y con las noticias que juzgara de interés para la Academia. Estatutos todos que se mantienen más o menos en vigencia hoy en día.

13 Abargues de Sostén, 1883.

14 Gómez de Valenzuela, 2002.

15 Congreso español..., 1883.

Congreso español..., 1884. Ponencia titulada «Intereses comerciales en el mar Rojo; necesidad de consulados y factorías para el desarrollo de nuestro comercio y apoyo de nuestras comunicaciones con Filipinas».

García Figueras, 1947: 100-102. 


\section{Don Juan Víctor Abargues de Sostén...}

16 Congreso español..., 1883: 497.

Pedraz Marcos, 2000: 122.

17 Vilar Ramírez, 1969: 178-184.

18 Pous, 1999. De entre 1879 y 1881, nos llegan noticias de la compra por parte del Museo Arqueológico Nacional de una colección de casi 200 piezas del Egipto antiguo propiedad del Sr. Abargues.

19 Abargues, 1895.

20 Bertaux, 1991: 26-30.

21 Castanhoso, 1564. El autor es uno de los participantes en esta campaña de 1541 , que describe detalladamente.

22 Bertaux, 1991: 83-93.

23 Vilar Ramírez, 1969: 173-174.

24 Abargues, 1883: 262-268.

25 Abargues, 1883: 244-249. Describe su acción dramáticamente, aunque con modestia, recalcando su deber como cristiano y como español. El sentir patriótico y de caballero andante, así como la continua afirmación de la fe cristiana son una constante en todo su relato, como en otros de la época. También es destacable la visión que se tenía entonces de Europa como civilizadora de los «pobres» nativos a los que creían ver hambrientos de la presencia y ayuda extranjeras, como señalan las últimas frases de su segunda conferencia.

García Figueras, 1947: 96-97. Este autor se hace eco de tales hazañas. Menciona un periódico francés de El Cairo, L'Égipte, que en octubre de 1881 habla de las persecuciones de las que son víctimas los misioneros lazaristas franceses y de la salvación de un grupo de ellos por el jefe de una expedición española. Menciona también una carta enviada a la Gaceta Algemaine-Zeitung por el explorador alemán Gerar Rholfs sobre este hecho. Y hay referencias a la ayuda prestada por Abargues al Dr. Stecker, alemán, y a los hermanos italianos Naretty, aunque sin especificar en qué consistió tal ayuda.

${ }^{26}$ Casi todos los investigadores que han estudiado este tema inciden en este punto en sus publicaciones.

27 Pedraz Marcos, 2000: 120-121. Papeles de Costa, Archivo Provincial de Huesca, C.109, Ca 108.17.

28 Vilar Ramírez, 1969: 194-196. Este fue el caso, por ejemplo, en 1898, del intento de envío de tropas a través del Canal de Suez en auxilio de Manila, vetado por el Jedive de Egipto con la excusa de neutralidad, siendo que poco antes se había admitido el tránsito sin restricciones en paz o en guerra por el Canal. En ello se vio la mano de Gran Bretaña, entonces favorable a los Estados Unidos y la mayor accionista del Canal.

* Deseo agradecer a la Sociedad Geográfica Española su amable trato y colaboración cuando mostré interés por este artículo, entonces agotado y que aún no estaba incluido en su página de internet.

\section{Bibliografía}

ABARGUES DE SostÉN, J. V. (1883): «Noticias acerca de la expedición científica, geográfica y comercial realizada en el África Oriental. Conferencia pronunciada el 20 de febrero de 1883 por D. Juan Víctor Abargues de Sostén" Boletín de la Sociedad Geográfica de Madrid Tomo XV, 233-325 (reproducido con total exactitud en el mismo año 


\section{Montserrat Mañé Rodríguez}

como separata de la Asociación española para la exploración del África con el título «Notas del viaje del señor D. J. V. Abargues de Sostén por Etiopía, Xoa, Zebul, Volo, Galas, etc.», Imprenta Fortanet, Madrid, 93 págs.).

- (1895): Echec au Roi: nouvelle historique de Grenade 1408 J.C., 810 H. Al Maaref, Le Caire.

BARRAS Y DE ARAGÓN, F. DE LAS (1952): «Viajeros españoles de los siglos XIX y XX. Estudios bio-bibliográficos" Boletín de la Real Sociedad Geográfica Tomo LXXXVIII, 7109 (Abargues de Sostén, Juan Víctor: 8-9).

Bertaux, P. (1991): África. Desde la prehistoria hasta los años sesenta Historia Universal Siglo XXI, Madrid.

Castanhoso, M. DE (1564): História das cousas que o mui esforçado capitão Dom Cristóvão da Gama fez nos Reinos do Preste João com quatrocentos Portugueses que sonsigo levou Europa-América, 1988. Col. A Aventura Portuguesa, 4, Lisboa.

CoNGRESO ESPAÑOL DE GEOGRAFÍA COLONIAL Y MERCANTIL. CIRCULAR Y EXTRACTO DE LAS ACTAS DE LAS SESIONES (1883) En el Boletín de la Sociedad Geográfica de Madrid Tomo XIV, 1er semestre, 464-500.

CoNGRESO ESPAÑOL DE GEOGRAFÍa COLONIAL Y MERCANTIL. LiBRo DE ACTAS (1884), Madrid, Fortanet, Tomos I y II.

CóRdobA ZoILo, J. Mª (1998): «Del Éufrates y el Tigris a las montañas de Omán. Algunas observaciones sobre viajes, aventuras e investigaciones españolas en Oriente Próximo" Arbor 635-636, 441-463.

García Figueras, V. (1947): «Don Juan Víctor Abargues de Sostén, explorador de Abisinia. Una figura poco conocida de los exploradores españoles en África en el siglo XIX»" Archivos del Instituto de Estudios Africanos Año 1, $\mathrm{n}^{\circ}$ 2, 91-107.

García Sepúlveda, Ma . P. y Navarrete Martínez, E. (2005): Relación de Miembros pertenecientes a la Real Academia de Bellas Artes de San Fernando (1752-1983, 19842004) Real Academia de Bellas Artes de San Fernando-Archivo Biblioteca, Madrid. Publicación en internet: http://portallengua.fsanmillan.org/portallengua/fcc/pdf/proyectolenguabasf/2.2.4.relación\%20academicos.pdf

Gómez DE VALENZUELA, M. (2002): «Juan Víctor Abargues, un viajero del XIX por el Nilo» Sociedad Geográfica Española (SGE)* 11, 108-111.

Pedraz Marcos, A. (2000): Quimeras de África. La Sociedad Española de Africanistas y Colonistas. El colonialismo español de finales del siglo XIX Polifemo, Madrid.

Pous, M. (1999): «Breve historia de las sedes, instituciones y colecciones arqueológicas del Museo Arqueológico Nacional» En La Cultura Ibérica a través de la fotografía de principios de siglo. Las colecciones madrileñas Catálogo de la Exposición celebrada en Madrid en el Museo Arqueológico Nacional (MAN), del 17 de noviembre de 1999 al 13 de febrero de 2000. http://www.ffil.uam.es/catalogo/madrid/pous.htm

Rodríguez Esteban, J. A. (1996): Geografía y colonialismo. La Sociedad Geográfica de Madrid (1876-1936) Universidad Autónoma de Madrid, Madrid.

- (1998a): «La Real Sociedad Geográfica de Madrid. La aventura intelectual (primera parte)" Cartographica 3, 24-25.

- (1998b): «La Real Sociedad Geográfica de Madrid. Exploraciones africanas (segunda parte)» Cartographica 4, 4-7.

VILAR RAMíREZ, J. B. (1969): «España en Suez, Mar Rojo y Adén durante el siglo XIX» en La judería de Tetuán (1489-1860) y otros ensayos Universidad de Murcia, Murcia, 163-196. 